\title{
Frontiers
}

in the Psychotherapy of Trauma \& Dissociation

\section{A Journal for a Culture of Collaborative, Science-Oriented, Clinical Thinking}

Andreas Laddis, MD

The Official Clinical Journal of the International Society for the Study of Trauma and Dissociation Andreas Laddis, MD 


\title{
Frontiers in the Psychotherapy of Trauma \& Dissociation
}

The Official Clinical Journal of the ISSTD

\section{EDITOR}

ANDREAS LADDIS, MD, Private Practice and Faculty, Boston University, School of Public Health, Boston, Massachusetts, USA

\author{
ASSOCIATE EDITOR \\ MARTIN J DORAHY, PhD, Professor, Department of Psychology, University of Canterbury, \\ Christchurch, New Zealand and The Cannan Institute, Brisbane, Australia
}

\section{EDITORIAL ASSISTANT}

COURTENAY CRUCIL, MA, RCC, Private Practice, Terrace, British Columbia, Canada

\begin{abstract}
Frontiers in the Psychotherapy of Trauma $\mathcal{E}$ Dissociation is published by the International Society for the Study of Trauma and Dissociation, Inc., 4201 Wilson Blvd Third Floor, Arlington, VA 22203
\end{abstract}

\section{Annual Subscription, Volume 4, 2020}

Online subscription is part of the membership dues of the International Society for the Study of Trauma and Dissociation. Visit https://www.isst-d.org/join-isstd/individualmember-benefits/.

Production and Advertising Office: ISSTD Headquarters, 4201 Wilson Blvd Third Floor, Arlington, VA 22203

Copyright $\odot 2020$ International Society for the Study of Trauma and Dissociation. All rights reserved. No part of this publication may be reproduced, stored, transmitted, or disseminated in any for or by any means without prior written permission from the International Society for the Study of Trauma and Dissociation. The publisher assumes no responsibility for any statements of fact or opinion expressed in the published papers. The appearance of advertising in this journal does not constitute an endorsement or approval by the publisher, the editor, the editorial board, or the board of directors of the International Society for the Study of Trauma and Dissociation of the quality or value of the product advertised or of the claims made of it by its manufacturer.

Subscriptions to this journal are acquired through membership in the International Society for the Study of Trauma and Dissociation only.

Visit https://www.isst-d.org/join-isstd/individual-memberhip-categories/.

Permissions. For further information, please write to info@isst-d.org.

\section{EDITORIAL BOARD}

ELIZABETH S BOWMAN, MD, Editor Emerita, Journal of Trauma \& Dissociation, Adjunct Professor of Neurology, Indiana University School of Medicine, Indianapolis, Indiana, USA

LAURA S. BROWN, PhD, Private Practice, Seattle, Washington, USA

RICHARD A CHEFETZ, MD, Private Practice, Faculty and Founding Member Institute of Contemporary Psychotherapy \& Psychoanalysis, Distinguished Visiting Lecturer: William Alanson White Institute of Psychiatry, Psychoanalysis \& Psychology, New York City, USA

CONSTANCE J DALENBERG, PhD, Trauma Research Institute, California School of Professional Psychology, San Diego, California, USA

J.K. JUDITH DANIELS, PhD, Faculty of Behavioural and Social Sciences, University of Groningen, The Netherlands

STEVEN N GOLD, PhD, Professor, Center for Psychological Studies, and Founding Director, Trauma Resolution \& Integration Program, Nova Southeastern University, Fort Lauderdale, Florida, USA ELIZABETH B HEGEMAN, PhD, Professor, Department of Anthropology, John Jay College of Criminal Justice, New York, New York, USA 
RICHARD P. KLUFT, MD, PhD Private Practice and Clinical Professor of Psychiatry, Temple University School of Medicine; Faculty Member, Philadelphia Center for Psychoanalysis,

Philadelphia, Pennsylvania, USA

CHRISTA KRÜGER, MD, Professor of Psychiatry, University of Pretoria, Pretoria, Gauteng, South Africa

KARLEN LYONS-RUTH, PhD, Professor of Psychology, Harvard Medical School, Cambridge, Massachusetts, USA

ALFONSO MARTÍNEZ-TABOAS, PhD, Professor, Albizu University, San Juan, Puerto Rico WARWICK MIDDLETON, MD, Adjunct Professor, Cannan Institute, Brisbane, Australia

ELLERT R. S. NIJENHUIS, PhD, Department of Psychiatry and Outpatient Department Mental Health Care Drenthe, Assen, The Netherlands

SANDRA PAULSEN, PhD, Bainbridge Institute for Integrative Psychology, Bainbridge Island, Washington, USA

VEDAT SAR, MD, Professor of Psychiatry, Koç University School of Medicine (KUSOM), Istanbul, Turkey

JOYANNA SILBERG, PhD, Trauma Disorders Program, Sheppard Pratt Health Systems, Baltimore, Maryland, USA

ELI SOMER, PhD, Professor, School of Social Work, University of Haifa, Israel

KATHY STEELE, MN, CS, Private Practice, Atlanta, Georgia, USA

ONNO VAN DER HART, PhD Emeritus Professor of Psychopathology of Chronic Traumatization, Department of Clinical and Health Psychology, Utrecht University, Utrecht, The Netherlands VICTOR WELZANT, PsyD, Sheppard Pratt Health Systems, Trauma Disorders Program

\section{REVIEWERS}

JOHN BRIERE, PhD, Associate Professor of Psychiatry and Psychology, University of Southern California Keck School of Medicine, Los Angeles, California, USA

SHELDON IZKOWITZ, PhD, Clinical Associate Professor of Psychology and Clinical Consultant, Postdoctoral Program, New York University, New York City, USA and Teaching Faculty \& Supervisor of Psychotherapy and Psychoanalysis, National Institute for Psychotherapies, New York City, USA

MARY-ANNE KATE, PhD Researcher at University of New England, Australia; University of New England, New South Wales, Australia

ULRICH F. LANIUS, PhD, Private Practice, West Vancouver, British Columbia, Canada

\section{SUPPORTERS}

ISSTD thanks its generous supporters whose contributions have made this publication possible:

Andreas Laddis, MD, USA

\section{The \\ Cannan \\ Institute}

Cannan Institute, Australia

Warwick Middleton, MD, Australia

Dana Ross, MD, Canada

Martin J. Dorahy, PhD, New Zealand

Kate McMaugh, Australia

Sara Y. Krakauer, USA

Paula Eagle, MD, USA 


\title{
EDITORIAL
}

\section{A JOURNAL FOR A CULTURE OF COLLABORATIVE, SCIENCE-ORIENTED, CLINICAL THINKING}

\author{
ANDREAS LADDIS, MD \\ Private Practice, Framingham, MA 01545, USA
}

This editorial is to announce ending the publication of Frontiers in the Psychotherapy of Trauma and Dissociation and to share my sadness, pride, and hopes as the Editor of Frontiers. With much pride and deep sadness I will reminisce about the vision and ambitions presented with the inaugural issue three years ago. Then, I will highlight a few particular collections of articles to demonstrate how, I believe, a clinical journal could become a great asset for ISSTD moving forward. It could be a powerful means for a culture of collaborative, science-oriented, clinical thinking in the Society. My hope is that Frontiers has stirred the ISSTD members' interest and expectations for a clinical journal dedicated to psychotherapy for complex, trauma-related mental disorders.

KEYWORDS culture; science-oriented; related disciplines

\section{INTRODUCTION}

In the May issue of the ISSTD News, Christa Kruger, the President of ISSTD, announced:

Members will still remember the excitement with which we had launched our own ISSTD clinical e-journal,...in October 2017...we have discovered that the self-publication of our clinical e-journal is not sustainable in terms of the financial and other resources that ISSTD has available. Exploration of the publishing market revealed that Frontiers in its current format

Corresponding Author: Andreas Laddis, MD; 18 Independence Lane; Shrewsbury MA 01545-6242; Tel no 508-320-7895; Fax no 508-872-6330; E-mail: aladdis@gmail.com. 
was not considered financially viable by external publishers. The Board has decided to suspend the publication of Frontiers as from July 2020.

I do remember the excitement with which we launched Frontiers. The Mission Statement for it said: "The Editor believes that clinicians' observations from testing the rationale for their interventions, for one patient and one treatment session at a time, are indeed the seed for ideas to update existing theories and for hypotheses to test experimentally." In the inaugural editorial (Laddis, 2017), I cherished the prospect of creating a forum where creative clinicians would present their clinical experiments for psychotherapy's improvement to a wide readership and would draw thoughtful commentaries. In that editorial, I also presented my sense of the limitations of psychotherapy as we know it and I cited the well-tested concepts from related disciplines as sources for psychotherapy's development.

I remember my gratitude to the authors of that inaugural issue, pioneers of psychotherapy for complex, trauma-related disorders, in adults and in children. That issue displayed those pioneers' competing approaches for making interpretations and interventions to break impasses in understanding a patient's psychodynamics, the very essence of psychodynamic therapy. One of the authors wrote about the evolution of his thinking, arriving at particular strategy and tactics, in treating patients specifically with Dissociative Identity Disorder. His logic was to keep various theories in mind while devising "intuitive and pragmatic" hypotheses, inspired by guessing "what sense the patient's phenomena are trying to communicate." The second author presented a comprehensive model of "trauma therapy." He arrived at that model with the "navigational instruments" of certain philosophical and theoretical "premises" about human nature and behavior as the source of his hypotheses. The authors of the third article described how they borrowed each other's disparate training to discern signs of traumarelated mental states in the stereotypical behavior, mostly nonverbal, of children with "developmental delays," often autism.

With Steve Frankel, as Co-Editor at the start, and Martin Dorahy as Associate Editor, we aimed for breadth and quality of manuscripts. We encouraged submissions from authors worldwide. The articles in this final issue are from Spain, Australia, Argentina, The Netherlands and Germany! We made an effort to include authors whom we knew for their creative clinical work, but who were timid about publishing. Our reviewers graciously offered detailed commentary and guidance for those novice authors.

I will cite the articles in one more issue of the journal, from January 2019, because I think of them as bolder, more spirited; a measure of maturity for Frontiers. That issue included commentaries on two articles published earlier, as well as rejoinders to those two commentaries. Deliberately promoting such discussion is how a journal can make the most of an author's contribution. In addition, one commentary and rejoinder focused on "therapeutic neutrality," which generated my interest in inviting two 
more commentaries on that topic. That term pertains to: a) The value of making and sharing with patients' judgments of the credibility of remembering who contributed to making past traumatic abuse happen, especially memories of extreme abuse, as in cultish organizations and satanic rituals; and b) Reasons for individual clinicians or ISSTD to take the legal and political risk of making public allegations of criminal acts and neglect in the context of patient abuse by particular social institutions and powerful individuals. Those issues had divided ISSTD members, more or less bitterly, until recently. The two invited commentaries cited progress in proving the prevalence and methods of extreme abuse in criminology and progress in understanding the nature of remembering. Then, they explained how that progress settled much of the controversy and has reduced that division.

I believe that a clinical journal should deliberately seek manuscripts from authors who upgrade clinical theories with findings and well-tested concepts from related disciplines. That is why Martin Dorahy and I worked hard to earn Sylvia Solinski's commitment to publish her articles in this final issue of Frontiers. The series of three articles is again about the nature of memory and the peculiarities of recovered memories of traumatic experiences in caretaking relationships. Solinski's scope of sources is encyclopedic. I found most useful her references to works from experimental psychology and social psychology, especially from the domains of developmental and social psychology, memory and cognition, memory and language, and the psychology of goals.

What did I learn as a therapist from those two earlier commentaries and from Solinski's articles about the nature of remembering? I learned that our role is to help patients make sense of who contributed to making past traumatic abuse happen, including the patient's own vulnerabilities. That is done by contemplating hypotheses about acts of omission or commission that might fill the gaps in a narrative of entrapment in a mistrusted, yet greatly needed caretaking relationship. Memories are the transient and varying outcomes of such stepwise contemplation. Our role is not to suggest bringing such contemplation to closure with one or another particular "fact" that a patient remembers.

I close with this illustration of what I myself learned from Frontiers. I hope that Frontiers has stirred ISSTD members' expectations for a clinical journal dedicated to psychotherapy for complex, trauma-related mental disorders. I hope that ISSTD will find the means to restart a clinical journal to continue the culture of collaborative, science-oriented thinking in the Society, the kind of culture that Frontiers so ably promoted. 